\title{
Aspects of Humoral Immunity in a Group of Children With Type 1 Diabetes and Thyroid Disorders
}

\author{
Gherbon Adriana, Assistant Professor, $\mathrm{MD}, \mathrm{PhD}$ \\ Department of Physiology
}

University of Medicine and Pharmacy "V. Babes" Timisoara, Romania

\section{doi: 10.19044/esj.2016.v12n36p18 URL:http://dx.doi.org/10.19044/esj.2016.v12n36p18}

\begin{abstract}
Patients with diabetes have a high prevalence of thyroid disease compared with non-diabetic population. In the case of type 1 diabetes, it is often associated with autoimmune endocrine and systemic diseases as: Graves-Basedow disease, autoimmune chonic thyroiditis (ACT), Addison's disease, celiac disease, pernicious anemia, myasthenia gravis, vitiligo, etc.. The purpose of this study is to determine the main aspects of humoral immunity in a group of children with type 1 diabetes and thyroid disorders. The studied group was represented by 83 cases ( 71 girls and 12 boys), aged between 7-17 years. They were used clinical, imaging, biochemical, hormonal and immunological parameters. Results: Prevalence of positive anthyroid antibodies (ACAT) in the study group was: Basedow - Graves disease $-100 \%$ (both), ACT $-85.18 \%$ antiTPO and $83.33 \%$ antiTg, euthyroid difusse goiter $-0 \%$ (both). In the case of children and adolescents with type 1 diabetes and ACT with positive antiTPO AB we notice that they had a younger onset age of diabetes $(4.86 \pm 3.94$ vs. $8.62 \pm 0.51$ years $)$, a longer duration of diabetes $(9.23 \pm 4.05$ vs. $8.12 \pm 0.64$ years $)$, elevated HbA1c values $(8.91 \pm 2.03$ vs.7, $55 \pm 1.96 \%)$ and lower TSH values $(12.00 \pm 23.7$ vs. $14.77 \pm 17.03 \mathrm{mIU} / \mathrm{ml})$ than those negative. Conclusions: It is recommended determination of antithyroid antibodies, particularly those antiTPO in children and adolescents with type 1 diabetes at onset of diabetes, or before puberty and, if they are positive should be tested the thyroid function annually to minimize the risk of undiagnosed hypothyroidism.
\end{abstract}

Keywords: Type 1 diabetes, thyroid diseases, children, humoral immunity.

\section{Introduction}

Patients with diabetes have a high prevalence of thyroid disease compared with non-diabetic population. In the case of type 1 diabetes, it is often associated with autoimmune endocrine and systemic diseases as: 
Graves-Basedow disease, Hashimoto thyroiditis, Addison's disease, celiac disease, pernicious anemia, myasthenia gravis, vitiligo, etc.. A particular association of type 1 diabetes with hypo-or hyperthyroidism is characteristic to autoimmune polyglandular syndrome (APS).

One of the prominent features of the APS is the presence of circulating autoantibodies to autoantigens normally present in the endocrine organs involved in the disease. Such autoantibodies can occur long before the appearance of the evident clinical diseases and are thus predictive of the possible onset of autoimmune disease later in life. Patients with any one of the two types of APS may have autoantibodies against the same antigens. The identification of circulating organ-specific autoantibodies provided the earliest and strongest evidence for the autoimmune pathogenesis of the APS (Aldasouqi et al, 2006).

Autoantibodies in patients with APS react with thyroid gland proteins, including thyroid peroxidase, thyroglobulin, and thyrotropin receptors (El Rehewy et al, 1981). While immunoglobulins against the thyrotropin receptor may stimulate or inhibit both thyroid gland activity and growth, no consistently discernible effect on thyroid function has yet been attributed to autoantibodies that recognize thyroid peroxidase or thyroglobulin Autoimmunity against the thyroid gland is distinctly unusual in APS-1, but is frequent in APS $-2 \mathrm{a}$ and $-2 \mathrm{~b}$. Children with GAD antibody positivity in particular have been demonstrated to have a higher risk for the development of anti-thyroid antibodies (Bonifacio et al, 2009).

An important responsibility for the clinician managing patients with single endocrine autoimmunity diseases is to determine those patients' risk for the occurrence of polyglandular disorders. Clues uncovered by a thorough history and physical examination may reveal the true multi-focal nature of a patient's condition (Aldasouqi et al, 2006).

Subclinical or "compensated" deficiencies, identified by elevations of tropic hormones (e.g., normal thyroxine but elevated TSH in Hashimoto's disease), reflect early gland destruction that may be detected during the evaluation of more overt disease in other glands. Once recognized, each individual hormone deficiency should be treated and monitored using the same therapeutic replacement regimens as those used for patients who have isolated gland dysfunction (Aldasouqi et al, 2006).

Suggested screening protocol is:for Addison's Disease evaluation of ACTH, electrolytes, morning cortisol, aldosterone level, DHEA-S; adrenocortical, steroidal cell or 21-hydroxylase autoantibodies with the frequency annual, antibody levels at time of diagnosis, for alopecia physical exam annual, for autoimmune thyroid disease thyroid function tests and antibody levels annual, for celiac disease tissue transglutaminase (tTG) - IgA levels, biopsies as needed annual, for pernicious anemia antiparietal cell 
antibody levels, $\mathrm{CBC}$, vitamin $\mathrm{B}_{12}$ every 5 years, for primary hypogonadism luteinizing and follicular stimulating hormone levels, estradiol or testosterone annual, for type 1 diabetes (T1DM) hemoglobin A1c, fasting glucose, autoantibodies (Eg, GAD-65, IA-2, and IAA) annual, antibody levels at time of diagnosis and every 3 to 5 years (Aldasouqi et al, 2006).

Family members of a proband with T1DM or APS $2 \mathrm{a} / 2 \mathrm{~b}$ should undergo focused history, exam and screening every three to five years with T1DM autoantibody levels, TSH, serum $\mathrm{B}_{12}$, and anti-adrenal antibody levels (Aldasouqi et al, 2006).

If a patient is found to have thyroiditis, family members should also be screened for thyroid autoantibodies and goiter also.

The key to successfully managing patients with an autoimmune endocrinopathy is to identify and treat their autoimmunities before they cause significant morbidity and mortality. The treatment of organ insufficiencies is identical whether it occurs in isolation or as part of an APS. Endocrine replacement therapy remains the cornerstone of their clinical management. Patient education about the nature of the disease is often critical to the early recognition of additional new autoimmunities, and as with any chronic diseases, individualized needs for psychosocial support must be assessed. Genetic counseling is also warranted and family members should be screened with the use of specific tests (Aldasouqi et al, 2006).

Systematic studies of the long-term prognosis in APS patients are lacking, but clinical impressions are that the APS-2 patients have rates of morbidity and mortality that are identical to those of the component diseases when they occur in isolation. Adrenal crises are still a significant cause of preventable mortality, and uncontrolled thyroid hormone imbalances can rarely present as emergencies, especially in the elderly. The complications of T1DM, both acute and chronic, are as important in the APS setting as in isolated pancreatic disease (Aldasouqi et al, 2006).

\section{Material and method}

\section{Investigated population}

The group of children was represented by 83 subjects aged between 7 17 years.

All children from the study group had type 1 diabetes.

In the studied group, the gender distribution of the children was 5.9 / 1 , represented by 71 girls $(85.54 \%)$ and 12 boys $(14.45 \%)$. 


\section{Methods of investigation}

The methods of investigation were represented by clinical data - case history, current status, imagistic- thyroid ultrasound, biochemical - for glycemic balance: fasting blood glucose, glycosylated hemoglobin, investigation of the thyroid gland: $\mathrm{TSH}, \mathrm{FT}_{4}, \mathrm{FT}_{3}$, thyroid antibodies.

Determination of plasma glucose was performed by enzyme technique with glucosooxidasis. Normal values were taken between $70-110$ $\mathrm{mg} \%$; diabetes mellitus - values equal or over $126 \mathrm{mg} \%$, impaired glucose tolerance - values between $110-125 \mathrm{mg} \%$ and the OGTT at $2 \mathrm{~h}$ between 140 - $200 \mathrm{mg} \%$ and impaired fasting glucose - values between 110 - $125 \mathrm{mg} \%$ and OGTT at $2 \mathrm{~h}$ under $140 \mathrm{mg} \%$.

Determination of $\boldsymbol{H b A l c}$ was achieved through the DiaStat for measuring $\mathrm{HbA} 1 \mathrm{c}$ reported to the total $\mathrm{HbA}$.

To determine the TSH level in plasma, the free fraction of triiodotironin $\left(\mathrm{FT}_{3}\right)$, and the plasma free fraction of thyroxin $\left(\mathrm{FT}_{4}\right)$ were performed a quantitative method ARCHITECT; witch is an immunological method, Chemilumnescent Microparticle Immunoassay (CMIA). Normal values were following: $\mathrm{TSH}=0.465-4.68 \mathrm{Miu} / \mathrm{ml}, \mathrm{FT}_{3}=3.69-10.4 \mathrm{pmol} / \mathrm{l}$, $\mathrm{FT}_{4}=10-28.2 \mathrm{pmol} / \mathrm{l}$.

The immunological parameters were represented by autoimmune thyroid markers - antibodies (antiTPO and antiTg antibodies).

To determine serum levels of antiTPO antibodies it was used the kit AxSYM antiTPO, an immunological method (Microparticle Enzyme Immunoassay) (MEIA). Normal values: antiTPO antibodies <35 IU/ml.

To determine serum levels of antiTg antibodies it was used the kit AxSYM antiTg, a MEIA method as well (Microparticle Enzyme Immunoassay). Normal values: antiTg antibodies <55 IU/ml.

Thyroid ultrasound was performed in all cases and allowed us to measure thyroid volume, thyroid study and the changes in parenchyma's density.

An increased density, uniform, characterizes normal thyroid parenchyma easily distinguished from the neck muscles that are hypo dens.

Inflammatory processes and autoimmune pathology appears hypo dens. The scale was assessed as being discreet + , moderate ++ and marked +++ .

In the autoimmune thyroid disease the parenchyma of the gland appears hypo dens.

Chronic autoimmune thyroid disorder appears with a hypoecogenity of the parenchyma and normal or increased thyroid volume. 


\section{Results and discussion}

Thyroid humoral immunity was assessed by measuring serum antiperoxidase (antiTPO AB) and antithyreoglobulin (antiTg AB) antibodies titres in whole lot patients.

Prevalence of positive anthyroid antibodies titer changes in the study group was for Basedow - Graves disease - 100\% (both AB), for ACT $85.18 \%$ antiTPO $\mathrm{AB}$ and $83.33 \%$ antiTg $\mathrm{AB}$ and for euthyroid difusse goiter $-0 \%$ (both $\mathrm{AB}$ ).

The incidence of antithyroid antibodies in patients with type 1 diabetes varies from one author to another, and it is estimated between $7-40 \%$ (Marginean et al, 2000). Percentage variability may occur due to different methods of investigation and study group homogeneity (ethnic differences, gender and age). The incidence of antithyroid antibodies is estimated at 20$30 \%$ in North America and at 6.3 to $14.2 \%$ in Western Europe [Marginean et al, 2000].

By gender, antithyroid antibodies are frequently found at the girls compared with boys (Marginean et al, 2000).

In patients with ACT, antithyreoglobulin antibody positivity occurs in $50 \%$ of patients, while the antiperoxidase antibody positivity in $90 \%$ of them (Marginean et al, 2000).

A study in Germany shows that between 3-50\% of patients with type 1 diabetes have positive antithyroid antibodies (ACAT) (Umpierrez et al, 2003). Another study in Germany shows that the prevalence of antithyroid antibodies increases with age, the highest prevalence being between 15-20 years (16.9\% antiTPO AB and $12.8 \%$ for antiTg AB) (Kordonouri, 2002).

This is supported by another study in Germany which shows that the raised ACAT prevalence is 3.7\% in those under 5 years and reach over $25.3 \%$ of those aged 15-20 years (Holl, 1999).

The higher value of antiTPO AB was found in patients with GravesBasedow disease $(1000 \pm 0 \mathrm{mIU} / \mathrm{ml})$ and the lowest in patients with euthyroid diffuse goiter $(8.05 \pm 7.29)$. In the case ACT, the medium value was $416.11 \pm$ $319.11 \mathrm{mIU} / \mathrm{ml}$.

Regarding antiTPO AB, in our group we obtained the results shown in Table 1.

Table 1. Prevalence of antiTPO AB titer changes in the study group

\begin{tabular}{|c|c|c|c|c|c|c|c|c|}
\hline \hline $\begin{array}{c}\text { AntiTPO } \\
\text { AB titer }\end{array}$ & \multicolumn{2}{|c|}{$\begin{array}{c}\text { Total } \\
(\mathrm{n}=83)\end{array}$} & \multicolumn{2}{c|}{$\begin{array}{c}\text { Graves- } \\
\text { Basedow } \\
\text { disease } \\
(\mathrm{n}=4)\end{array}$} & \multicolumn{2}{|c|}{$\begin{array}{c}\text { ACT } \\
(\mathrm{n}=54)\end{array}$} & \multicolumn{2}{|c|}{$\begin{array}{c}\text { Euthyroid } \\
\text { difusse goiter } \\
(\mathrm{n}=25)\end{array}$} \\
\cline { 2 - 11 } & $\mathrm{n}$ & $\%$ & $\mathrm{n}$ & $\%$ & $\mathrm{n}$ & $\%$ & $\mathrm{n}$ & $\%$ \\
\hline \hline Higher & 50 & 60.24 & 4 & 100 & 46 & 85.18 & - & - \\
\hline Normal & 33 & 39.76 & - & - & 8 & 14.81 & 25 & 100 \\
\hline
\end{tabular}


A study in Poland showed that raised antithyroid antibodies were present in $17.8 \%$ of children, at those who these were present were older, and insulin requirements did not differ between those with positive and negative ACAT (Czerniawska et al, 2003).

A study in Germany on 216 patients with a mean age of 12.9 years has shown that raised antiTPO antibodies were present in $10 \%$ of cases, antiTg antibodies in $8.7 \%$ and both in $5.9 \%$ cases (Kordonouri, 2002).

Another study conducted in Spain indicate that the children with positive ACAT were older and had higher levels of TSH to those with negative ACAT (Lopez Medina et al, 2004).

Table 2. Comparative data (p) between cases antiTPO AB positive and negative in patients with ACT from the study group

\begin{tabular}{|c|c|c|c|}
\hline \hline Parameters & $\begin{array}{c}\text { Negative antiTPO } \\
\mathrm{AB}\end{array}$ & $\begin{array}{c}\text { Positive antiTPO } \\
\mathrm{AB}\end{array}$ & $\mathrm{p}$ \\
\hline \hline Cases number $(\%)$ & $8(8 \mathrm{~F})$ & $46(7 \mathrm{M} \mathrm{şi} \mathrm{39} \mathrm{F)}$ & $<0.001$ \\
\hline Age (years) & $16.75 \pm 0.46$ & $14.06 \pm 2.37$ & $<0.001$ \\
\hline Onset age of DM (years) & $8.62 \pm 0.51$ & $4.86 \pm 3.94$ & $<0.001$ \\
\hline DM duration (years) & $8.12 \pm 0.64$ & $9.23 \pm 4.05$ & 0.087 \\
\hline BMI (kg/m $)$ & $19.72 \pm 1.57$ & $20.79 \pm 2.82$ & 0.14 \\
\hline HbA $(\%)$ & $7.55 \pm 1.96$ & $8.91 \pm 2.03$ & 0.10 \\
\hline Glycemia $(\mathrm{mg} \%)_{\mathrm{TSH}^{2}(\mathrm{mIU} / \mathrm{ml})}^{183.75 \pm 90.09}$ & $149.67 \pm 59.2$ & 0.33 \\
\hline $\mathrm{FT}_{4}(\mathrm{pmol} / \mathrm{l})$ & $14.77 \pm 17.03$ & $12.00 \pm 23.7$ & 0.69 \\
\hline & $13.5 \pm 10.1$ & $7.59 \pm 6.57$ & 0.15 \\
\hline
\end{tabular}

In the case of children and adolescents with type 1 diabetes and ACT with positive antiTPO AB we notice that they had a younger onset age of diabetes (4.86 \pm 3.94 vs. $8.62 \pm 0.51$ years), a longer duration of diabetes $(9.23$ \pm 4.05 vs. $8.12 \pm 0.64$ years $)$, elevated HbAlc values $(8.91 \pm 2.03$ vs. $7,55 \pm$ $1.96 \%)$ and lower TSH values $(12.00 \pm 23.7$ vs. $14.77 \pm 17.03 \mathrm{mIU} / \mathrm{ml})$ than those with negative antiTPO AB (Table 2).

All 8 cases with negative antiTPO AB were under treatment with thyroid hormones for $\sim 1-2$ years. It is possible that at onset these cases presented subclinical hypothyroidism and positive antiTPO AB. After treatment was obtain the balance of thyroid status and negative antiTPO AB, but with raised antiTg $\mathrm{AB}$ persistence.

The incidence of positive antiTg AB titres was the same as for antiTPO antibodies. In the case of ACT, 45 cases present antiTg antibodies raised (Table 3). 
Table 3. Prevalence of antiTg AB titre changes in the study group

\begin{tabular}{|c|c|c|c|c|c|c|c|c|}
\hline \hline $\begin{array}{c}\text { AntiTg } \\
\text { AB titers }\end{array}$ & \multicolumn{2}{|c|}{$\begin{array}{c}\text { Total } \\
(\mathrm{n}=83)\end{array}$} & \multicolumn{2}{c|}{$\begin{array}{c}\text { Graves-Basedow } \\
\text { disease } \\
(\mathrm{n}=4)\end{array}$} & \multicolumn{2}{c|}{$\begin{array}{c}\text { ACT } \\
(\mathrm{n}=54)\end{array}$} & \multicolumn{2}{|c|}{$\begin{array}{c}\text { Euthyroid } \\
\text { difusse goiter } \\
(\mathrm{n}=25)\end{array}$} \\
\cline { 2 - 10 } & $\mathrm{n}$ & $\%$ & $\mathrm{n}$ & $\%$ & $\mathrm{n}$ & $\%$ & $\mathrm{n}$ & $\%$ \\
\hline \hline Higher & 49 & 59.03 & 4 & 100 & 45 & 83.33 & - & - \\
\hline Normal & 34 & 40.97 & - & - & 9 & 16.66 & 25 & 100 \\
\hline
\end{tabular}

In the entire group of children, both antithyroid antibodies were present in 49 subjects. In patients with Graves-Basedow disease, all 4 patients had both antibodies raised, and in those with ACT, 45 subjects had both antibodies raised.

In Europe have been numerous studies on the prevalence of antiTPO $\mathrm{AB}$ in children with various thyroid diseases such as:

* UK: study on 65 patients with Hashimoto's thyroiditis and on 38 patients with Graves-Basedow disease showed that antiTPO antibodies were positive in $86 \%$ of those with Hashimoto's thyroiditis and $87 \%$ of GravesBasedow disease: ifn the case of antiTg antibodies, the proportion of positive results was much lower, 58\% and 73\% (Gilmour et al, 2000)

- Serbia: antiTPO antibodies were positive in almost all patients with Hashimoto's thyroiditis and $75 \%$ of patients with Graves-Basedow disease (Trbojevic et al, 2005)

* France: antiTPO antibodies were present in $40.5 \%$ of patients with Hashimoto thyroiditis and $34.6 \%$ of Graves-Basedow disease (Estienne et al, 1999)

* Germany: from 659 patients, $15.4 \%$ had elevated antiTPO AB and $14.4 \%$ antiTg $\mathrm{AB}$, girls were more affected than boys (Kordonouri et al, 2005)

- Poland: on a sample of 219 children and adolescents, the authors found higher titre of antiTPO AB in $34.7 \%$ of cases, also predominantly in females (Kalicka-Kasperczyk et al, 2003)

In our study, regarding the presence of ACAT, significant differences were found between their titres in patients with Graves-Basedow disease and ACT (autoimmune diseases) than those with diffuse euthyroid goiter (Table $4)$.

A study in Germany shows that 8 of 16 patients with positive ACAT showed elevated TSH after 2-6 years (median 3.5 years). Therefore the authors recommended that annual TSH determination in patients with positive ACAT. 
Table 4. Prevalence of ACAT in the group of children of adolescent

\begin{tabular}{|c|c|c|c|c|}
\hline \hline Thyroid disease & \multicolumn{2}{|c|}{$\begin{array}{c}\text { AntiTPO AB significant } \\
\text { titers }\end{array}$} & \multicolumn{2}{c|}{$\begin{array}{c}\text { AntiTg AB significant } \\
\text { titers }\end{array}$} \\
\cline { 2 - 5 } & $\mathrm{n}$ & $\%$ & $\mathrm{n}$ & $\%$ \\
\hline \hline Graves-Basedow disease & 4 & $100 \%$ & 4 & $100 \%$ \\
\hline ACT & 46 & $85.18 \%$ & 45 & $83.33 \%$ \\
\hline Euthyroid difusse goiter & - & - & - & - \\
\hline
\end{tabular}

Also, German Society of Pediatrics recommends that patients with positive ACAT, with increased thyroid volume and with hypoecogen typical aspect at thyroid ultrasound to be treated with L-thyroxine (Kordonouri et al, 2003).

Contradictory results show an U.S. study that recommends to test first TSH and then ACAT. The authors show that did not receive any benefit from the treatment of patients with normal TSH values (Hoffman et al, 2003).

Annual determination of TSH in patients with type 1 diabetes for early identification of thyroid dysfunction is supported by other studies (Ditta et al, 2001).

Depending on age groups, we obtained the following results in patients with ACT regarding ACAT (Table 5).

Table 5. ACAT titer by age in patients with ACT

\begin{tabular}{|c|c|c|c|}
\hline \hline Age & $\mathrm{n}$ & AntiTPO AB & AtiTg AB \\
\hline \hline 7-9 years & 2 & $802.5 \pm 928.36$ & $518.4 \pm 681.08$ \\
\hline 10-14 years & 21 & $632.74 \pm 192.00$ & $911.38 \pm 226.31$ \\
\hline 15-17 years & 31 & $244.45 \pm 230.99$ & $402.05 \pm 314.89$ \\
\hline
\end{tabular}

We obtained significant differences in the amount of ACAT between the age groups 10-14 years and 15-17 years ( $\mathrm{p}<0.001)$, values being higher in the age group 10-14 years (puberty) to age group 15 to 17 years (adolescence).

Following study and correlation of data referred to 54 cases were found morphofunctional different forms of thyroid disease (Table 6).

Highest incidence was owned by ACT with eutiroidism, detected in 28 patients. Of these, 15 cases presented with goiter and 13 cases eutiroidism eutiroidism without goiter (asymptomatic).

ACT with hypothyroidism was diagnosed in 26 patients. A total of 18 subjects were presented ACT with hypothyroidism and goiter and 8 subjects ACT with hypothyroidism without goitre. Also, 8 subjects had subclinical hypothyroidism and 18 subjects clinical hypothyroidism.

Basedow disease was present in 4 cases (1 with and 3 without goiter goiter).

Goiter was present in 25 cases, all 25 cases were euthyroid. 
Table 6. Distribution of thyroid disease cases on morpho-functional groups

\begin{tabular}{|c|c|c|c|c|c|c|}
\hline \hline \multirow{2}{*}{$\begin{array}{c}\text { Type/severity } \\
\text { Thyroid disease }\end{array}$} & \multicolumn{2}{|c|}{$\begin{array}{c}\text { ACT } \\
(\mathrm{n}=54)\end{array}$} & \multicolumn{2}{c|}{$\begin{array}{c}\text { Graves- } \\
\text { Basedow } \\
\text { disease } \\
(\mathrm{n}=4)\end{array}$} & \multicolumn{2}{c|}{$\begin{array}{c}\text { Euthyroid diffuse } \\
\text { goiter (n =25) }\end{array}$} \\
\cline { 2 - 8 } & $\mathrm{n}$ & $\%$ & $\mathrm{n}$ & $\%$ & $\mathrm{n}$ & $\%$ \\
\hline \hline Hypothyroidism & 26 & 48.14 & - & - & - & - \\
\hline - with goiter & 18 & 69.23 & - & - & - & - \\
\hline - without goiter & 8 & 30.77 & - & - & - & - \\
\hline Euthyroidism & 28 & 51.85 & - & - & 25 & 100 \\
\hline - with goiter & 15 & 53.57 & - & - & 25 & 100 \\
\hline - without goiter & 13 & 46.43 & - & - & - & - \\
\hline Hyperthyroidism & - & - & 4 & 100 & - & - \\
\hline - with goiter & - & - & 1 & 25 & - & - \\
\hline - without goiter & - & - & 3 & 75 & - & - \\
\hline
\end{tabular}

In the case of ACT, depending on the clinical form, we obtained two groups:

- ACT with hypothyroidism

- ACT with eutiroidism

In each group we appreciated the onset age of diabetes, current age, diabetes duration, BMI and sex. There were no significant differences in these parameters in the 2 groups (Table 7 and 8 ).

Euthyroid ACT was present in 28 cases $(51.85 \%)$, predominantly in girls - 25 cases (89.28\%). At diagnosis, mean age of type 1 diabetes was 7.96 \pm 3.75 years.

Hashimoto ACT with hypothyroidism was present in 26 cases (48.15\%), gender distribution is $\mathrm{F} / \mathrm{M}=22 / 4$, the average age of type 1 diabetes was $10.26 \pm 3.44$ years, so superior circumstance prior.

Table 7. Comparative data (p) between ACT with and without hypothyroidism in the studied children group

\begin{tabular}{|c|c|c|c|}
\hline Parameters & $\begin{array}{c}\text { ACT with } \\
\text { hypothyroidism } \\
(\mathrm{n}=26)\end{array}$ & $\begin{array}{c}\text { ACT with } \\
\text { euthyroidism } \\
(\mathrm{n}=28)\end{array}$ & $\mathrm{p}$ \\
\hline Male & 4 & 3 & 0.61 \\
Female & 22 & 25 & 0.61 \\
\hline BMI $\left(\mathrm{kg} / \mathrm{m}^{2}\right)$ & $21.4 \pm 2.62$ & $19.92 \pm 2.59$ & 0.04 \\
\hline antiTPO AB & $373.47 \pm 285.54$ & $455.72 \pm 347.88$ & 0.34 \\
\hline $\begin{array}{c}\text { Onset age of DM } \\
\text { type 1 (years) }\end{array}$ & $4.53 \pm 3.69$ & $6.25 \pm 3.93$ & 0.10 \\
\hline Current age (years) & $14.73 \pm 2.01$ & $14.21 \pm 2.72$ & 0.42 \\
\hline $\begin{array}{c}\text { DM type 1 duration } \\
\text { (years) }\end{array}$ & $10.26 \pm 3.44$ & $7.96 \pm 3.75$ & 0.02 \\
\hline
\end{tabular}


Table 8. Characteristics of different forms of ACT in the studied group of children and adolescents with type 1 diabetes

\begin{tabular}{|c|c|c|c|c|}
\hline \multirow{2}{*}{ Characteristics } & \multicolumn{2}{|c|}{ ACT with hypothyroidism } & \multicolumn{2}{c|}{ ACT with euthyroidism } \\
\cline { 2 - 5 } & $\begin{array}{c}\text { Without } \\
\text { goiter }\end{array}$ & With goiter & $\begin{array}{c}\text { Without } \\
\text { goiter }\end{array}$ & With goiter \\
\hline Cases number & 8 & 18 & 13 & 15 \\
\hline Male & 0 & 4 & 0 & 3 \\
\hline Female & 8 & 14 & 13 & 12 \\
\hline Age (years) & $14.25 \pm 2.49$ & $14.94 \pm$ & $13.92 \pm$ & $14.46 \pm 2.85$ \\
& & 1.79 & 2.66 & \\
\hline $\begin{array}{c}\text { Onset age of DM } \\
\text { (years) }\end{array}$ & $5.62 \pm 3.11$ & $4.05 \pm 3.9$ & $\begin{array}{c}4.84 \pm \\
2.88\end{array}$ & $7.46 \pm 4.38$ \\
\hline $\begin{array}{c}\text { DM duration } \\
\text { (years) }\end{array}$ & $8.62 \pm 0.91$ & $11 \pm 3.91$ & $9.07 \pm$ & $7 \pm 4.44$ \\
\hline
\end{tabular}

A study in Italy on 160 children, 43 boys and 117 girls, mean age of $9.1 \pm 3.6$ years, with Hashimoto's thyroiditis, showed that the presence of goiter and antiTg $\mathrm{AB}$ raised in onset, together with increased AntiTPO AB and $\mathrm{TSH}$, are predictors for the subsequent appearance of hypothyroidism (Kalicka-Kasperczyk et al, 2003).

In a study conducted in Germany showed that the antiTPO antibody prevalence increases with age (Kordonouri et al, 2002). In a recent study, Jaeger et al. (2001) showed a significant increase of antiTPO AB titres with recent onset of diabetes (Kordonouri et al, 2003). Other studies have shown that females are more prone to autoimmune thyroid disease at any age (Kordonouri et al, 2002).

It is also shows that the subjects with the antibody antiTPO positive or both positive ACAT have significantly elevated levels of TSH, hypoechogenity and increase in volume of the thyroid gland (Kordonouri et al, 2002).

Padberg et al. (2001) confirms that those with the antiTPO antibody positive have elevated levels of TSH, they are more sensitive than antiTg antibodies to diagnose autoimmune thyroid disease (Hoffman, 2003).

In a German study only $10.5 \%$ of patients with autoimmune thyroid damage were treated with L-thyroxine. This reflects the contradictory discussions of literature concerning the effectiveness of therapy in euthyroid patients with thyroid hormones (TSH and $\mathrm{FT}_{4}$ concentrations of normal) and in patients with subclinical hypothyroidism (elevated TSH concentration and normal $\mathrm{FT}_{4}$ ) (Hoffman, 2003, Ditta et al, 2001).

Rother et al. (1994) showed that most children and adolescents with normal $\mathrm{FT}_{4}$ not respond to replacement therapy by reducing goiter, even if they have normal or elevated TSH levels (Kordonouri et al, 2002). On the other hand, Padberg et al. (2001) show a significant reduction in levels of TSH and antiTPO AB in euthyroid patients with thyroid autoimmune disease after 1 
year of treatment with L-thyroxine, compared with those untreated (Ditta et al, 2001).

Engler et al. (1992) estimated the risk of clinical hypothyroidism after 10 years to $63 \%$ in patients with increased TSH and positive antiTPO AB, compared with $22 \%$ in those with isolated increase in TSH. Chase et al. reported reduced growth rate in children with diabetes and subclinical hypothyroidism, especially for TSH values above $50 \mathrm{mU} / \mathrm{L}$. After the treatment with L-thyroxine was found to increase during the prepubertal growth. The German study reported no significant differences in terms of glycemic control in the 2 groups and the growth rate (Kordonouri et al, 2002).

Other studies have shown the association of celiac disease with type 1 diabetes and autoimmune thyroid disease (Jaeger et al, 2001, Padberg et al, 2001). Diabetic patients with autoimmune thyroid damage with or without antithyroid antibodies do not appear to have a high prevalence of celiac disease (Cooper, 2001, Meloni et al, 2001).

\section{Conclusion}

In conclusion, there seems to be an inherent tendency to develop an autoimmune response against specific molecules of target organs in the majority of immunologically mediated endocrine diseases. The inheritance pattern of these diseases aids in the diagnosis of autoimmune disorders such as APS-1, T1DM and Addison's disease before progression to clinical onset in first-degree relatives of affected individuals. The diagnostic approach for these autoimmune mediated endocrine diseases is then based on genetic ascertainments, but can be complemented by the detection of a combination of immunologic markers with high predictive value.

The immunological markers for thyroid diseases are antiTPO and antiTg AB, the most important and usefull being determination of antiTPO AB.

However, it is recommended determination of antithyroid antibodies, particularly those antiTPO in children and adolescents with type 1 diabetes at onset of diabetes, or before puberty. In the case of positive antibodies should be tested the thyroid function (annually) and perform thyroid ultrasound to minimize the risk of undiagnosed hypothyroidism in young patients with type 1 diabetes.

\section{References:}

1. Aldasouqi, S.A., Akinsoto, O.P.A., Jabbour, S.A. (2006). Polyglandular AutoimmuneSyndrome, Type I, In Endocrinology (electronic book), pag. 1 - 18

2. Bonifacio, E., Mayr A., Knopff A., Ziegler A. (2009). Endocrine autoimmunity in families with type 1 diabetes: frequent appearance of 
thyroid autoimmunity during late childhood and adolescence. Diabetologia 52:p185

3. Cooper, D. (2001). Subclinical hypothyroidism. N Engl J Med; 345: $260-265$

4. Czerniawska, E., Szalecki, M., Piatkowska, E., Mlynarski, W., Bodalski, J., Lewinski, A. (2003). Prevalence of thyroid antibodies (TPO and ATG) at the onset of type 1 diabetes mellitus in children treated in two diabetes centres in Lodz and Kielce, Med Wieku Rozwoj; 7 (2): $223-8$

5. Ditta, A., Tayyab, M., Qavi, A., Malik, M.A., Chaudhry, N.A. (2001). Significance of thyrotrophin and thyroxine estimations in type 1 diabetes, J Pak Med Assoc; 51 (10): 349 - 51

6. El Rehewy, M., Kong, Y. M., Giraldo, A. A., and Rose, N.R. (1981). Syngeneic thyroglobulin is immunogenic in good responder mice. Eur J Immunol 11:p146

7. Estienne, V., Duthoit, C., Costanzo, V.D., Lejeune, P.J., Rotondi, M., Kornfeld, S., Finke, R., Lazarus, J.H., Feldt-Rasmussen, U., Franke, W.G., Smyth, P., D’Herbomez, M., Conte-Devolx, B., Persani, L., Carella, C., Jourdain, J.R., Izembart, M., Toubert, M.E., Pinchera, A., Weetman, A., Sapin, R., Carazon, P., Ruf, J. (1999). Multicenter study on TGPO autoantibody prevalence in various thyroid and non-thyroid diseases; relationships with thyroglobulin and thyroperoxidase autoantibody parameters, Eur J Endocrinol; 141 (6): 563 - 9

8. Gilmour, J., Brownlee, Y., Foster, P., Geekie, C., Kelly, P., Robertson, S., Wade, E., Braun, H.B., Staub, U., Michel, G., Lazarus, J.H., Parkes, A.B. (2000). The quantitative measurement of autoantibodies to thyroglobulin and thyroid peroxidase by automated microparticle based immunoassays in Hashimoto's disease, Graves' disease and a follow-up study on postpartum thyroid disease, Clin Lab; 46 (1-2): 57 $-61$

9. Hoffman, R.P.(2003).Thyroid stimulating hormone screening is more sensitive for detecting thyroid abnormalities in children and adolescents with type 1 diabetes. Diabetes Care, 26: 255

10. Holl, R.W., Bohm, B., Loos, U., Grabert, M., Heinze, E., Homoki, J. (1999). Thyroid autoimmunity in children and adolescents with type 1 
diabetes mellitus. Effect of age, gender and Hla type, Horm Res; 52 (3): $113-8$

11. Jaeger, C., Hatziagelaki, E., Petzoldt, R., Bretzel, R.G. (2001). Comparative analysis of organ-specific autoantibodies and celiac disease-associated antibodies in type 1 diabetic patients, their firstdegree relatives, and healthy control subjects. Diabetes Care; 24: 27 32

12. Kalicka-Kasperczyk, A., Dziatkowiak, H., Nazim, J., PituchNoworolska, A., Kasperczyk, K., Bartnik-Mikuta, A., Sztefko, K., Starzyk, J. (2003). Thyroid peroxidaze antibodies and thyroid diseases in children and adolescents with type 1 diabetes mellitus from Southeast Poland, Przegl Lek; 60 (6): 403 - 6

13. Kordonouri, O., Hartmann, R., Holl, R.W. (2003). Thyroid Antibody Screenind in Children and Adolescents With Type 1 Diabetes, Diabetes Care; 26: 255 - 256

14. Kordonouri, O., Deiss, D., Danne T., Dorow, A., Bassir, C., GrutersKieslich, A. (2002). Predictivity of thyroid autoantibodies for the development of thyroid disorders in children and adolescents with Type 1 diabetes, Diabet Med;19 (6): 518 - 21

15. Kordonouri, O., Klinghammer, A., Lang, E.B., Gruters-Kieslich, A., Grabert, M., Holl, R.W. (2002). Thyroid autoimmunity in children and adolescents with type 1 diabetes: a multicenter survey, Diabetes Care; 25 (8): $1346-50$

16. Kordonouri, O., Hartmann, R., Deiss, D., Wilms, M., Gruters Kieslich, A. (2005). Natural course of autoimmune thyroiditis in type 1 diabetes: association with gender, age, diabetes duration, and puberty, Arch Dis Child; 90 (4): 411 - 4

17. Lopez Medina, J.A., Lopez-Jurado Romero de la Cruz, R., Delgado Garcia, A., Espigares Martin, R., Barrionuevo Porras, J.L., Ortega Martos, L. (2004). Beta-cell, Thyroid and celiac autoimmunity in children with type 1 diabetes, An Pediatr (Barc); 61 (4): 320 - 5

18. Mărginean, O., Micle, I. (2000). Autoimmune diseases associated with diabetes mellitus type 1: Paediatric Diabetology, theory and practice (pp. 407 - 423), Marineasa Publishing

19. Meloni, G.F., Tomasi, P.A., Bertoncelli, A., Fanciulli, G., Delitala, G., Meloni, T. (2001). Prevalence of silent celiac disease in patients with 
autoimmune thyroiditis from Northern Sardinia. J Endocrinol Invest; 24: 298 - 302

20. Padberg, S., Heller, K., Usadel, K.H., Schumm - Draeger, P.M. (2001). One - year prophylactic treatment of euthyroid Hashimoto's thyroiditis patients with levothyroxine:is there a benefit?.Thyroid; 11: $249-255$

21. Trbojevic, B., Djurica, S. (2005). Diagnosis of autoimmune thyroid disease, Srp Arh Celok Lek; 133 Suppl 1: 25 - 33

22. Umpierrez Guillermo, E., Kashif, A. (2003). Thyroid dysfunction in patients with type 1 diabetes. Diabetes Care; 26: 1181 - 1185 